\title{
DESIGN, IDENTIDADE, CULTURA E TERRITÓRIO: UMA ANÁLISE DO DESIGN CÊNICO NO ESPETÁCULO “A MANDIOCA BRAVA"
}

\author{
Yuri Simon da Silveira \\ Escola de Design - UEMG \\ yuri.silveira@uemg.com \\ Dijon De Moraes \\ Escola de Design - UEMG \\ dijon.moraes@uemg.br
}

\begin{abstract}
Resumo: Este artigo analisa, a partir dos conceitos de Design e Território, Identidade Cultural e Multiculturalismo, as criações e as configurações elaboradas para a montagem do espetáculo "A Mandioca Brava", observando de que forma a montagem teatral se utilizou dos elementos e dos símbolos inerentes da cultura regional a partir da manipulação dos signos visuais e verbais. Os aspectos de mineiridade estão presentes tanto no discurso quanto no vocabulário e na musicalidade, bem como nas imagens produzidas pelo conjunto visual, que se pode chamar de design cênico, estabelecido pelos signos visuais do espetáculo: a cenografia, a iluminação e a caracterização dos personagens (obtida por meio do figurino, da maquiagem e da composição corporal dos atores). Um espetáculo que, em sua configuração final, deixa evidente a importância de se levar em consideração a utilização de elementos visuais da cultura regional com o propósito de se criar um sentimento de identificação e empatia nos espectadores do espetáculo.
\end{abstract}

Palavras-chave: Design e Território, Multiculturalismo, Identidade, Teatro, Design Cênico.

Abstract: This article analyses the creations and settings to the theatrical play "A Mandioca Brava", using Design and Territory, Cultural Identity and Multiculturalism concepts. This has been done observing the manner that the theatrical play applied inherent elements and symbols of regional culture through visual and verbal signs. The Minas Gerais state's way of being is present not only in the speech, but also in the vocabulary and in the musicality, as well as in the images produced by the visual set. This visual set, which can be called 'scenic design', is established by the visual signs of the play: scenography, lighting and characterization of the characters (built through the costumes, make up and body composition of the actors). A theatrical play that, in its final setting, makes evident the importance of considering the utilization of regional culture's visual elements in order to create an identification and empathy feeling in the audience.

Keywords: Design and Territory, Multiculturalism, Identity, Theatre, Scenic Design 


\section{INTRODUÇÃO}

O espetáculo "A Mandioca Brava" é uma montagem teatral belorizontina inspirada na clássica obra de Nicolau Maquiavel "A Mandrágora". Teve sua estreia no final de 2013 e continua se apresentando desde essa época. Trata-se de um espetáculo que foi realizado a partir de uma extensa pesquisa na cultura popular e no folclore de Minas Gerais, elementos que podem ser observados em todos os aspectos e características apresentadas pela encenação teatral.

O texto, inicialmente erudito por se tratar de uma obra renascentista de Maquiavel, fora adaptado para um vocabulário e linguajar mineiros, que mesclam o tradicional interiorano e o contemporâneo da capital. A peça conta, ainda, com uma trilha sonora original que se inspira na musicalidade regional, sem deixar de apresentar sonoridades atuais, e com características visuais de cenário, de iluminação, de figurino, de maquiagem e de composição corporal, que têm forte influência dos aspectos iconográficos e materiais observados na produção artesanal de Minas Gerais.

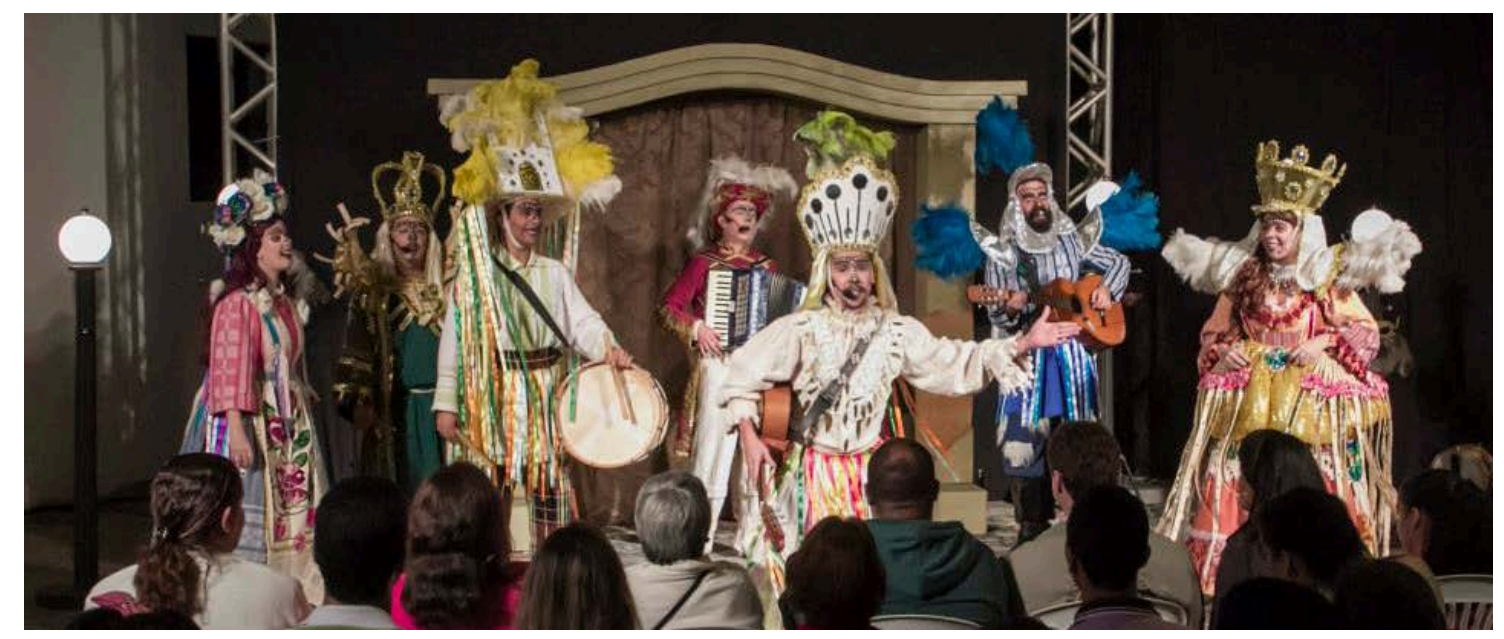

Figura 1 - Foto de uma apresentação na rua do espetáculo “A Mandioca Brava”

Fonte: Marco Aurélio Prates (https://www.facebook.com/amandiocabrava/photos_stream)

\section{O QUE É CULTURA}

É importante definir aqui o conceito de cultura e as diferenças entre o que se pode denominar cultura erudita e cultura popular, bem como as questões que envolvem a diferenças entre a cultura popular e o folclore. A partir do texto de Rosimeri Pichler, podemos afirmar que cultura corresponde aos "[...] valores e significados das pessoas e coisas, atuando de forma a regular as atividades da sociedade, relacionando-se com o desenvolvimento intelectual e espiritual e que se objetiva através de produtos culturais.", afirma ainda que "[...] a cultura é um processo de produção de significados que são capazes de manter ou modificar maneiras de viver, ideias e valores." (PICHLER e MELLO, 2012, p. 2). Pichler acrescenta que a cultura influencia na constituição de valores do indivíduo, na tomada de decisões, na forma de ver e compreender o mundo, e acompanha as mudanças da sociedade, sofrendo modificações constantes devido à sua dinamicidade.

ROCHA (2009) afirma que a diferença entre cultura popular e cultura erudita recebe atenção especial dos intelectuais desde o século XVIII na Europa. Para PICHLER 
e MELLO (2012), a cultura erudita, ou alta cultura, é aquela considerada cultura letrada ou acadêmica, que se legitima pela qualidade e, também, como expressão da elite ou classe hegemônica. Já a cultura popular é aquela que tem a potencialidade de ser a cultura do povo, se opondo à cultura da elite. Possui espontaneidade, principalmente por não vir de um sistema de educação formal, e, por isso, sendo resultante de uma experiência coletiva, em muitos casos, não sendo valorizada como legítima, por possuir independência em sua produção, reprodução e não necessariamente preocupações mercantis.

Já para COSTA (2008), a partir do modernismo, houve um movimento de resgate das tradições culturais no Brasil. No entanto, a autora afirma que isso ocorreu porque setores hegemônicos passaram a considerar lucrativas as características folclóricas da cultura popular, e porque, a partir da cultura popular, poder-se-ia remontar o que poderia vir a ser a construção de uma nação brasileira com o resgate do homem do interior e das tradições culturais. Diferentemente do que aconteceu na Europa, onde o modernismo tendeu a eliminar tradições e academicismos recorrentes na arte, como uma tabula rasa nas técnicas e processos, Costa afirma que "No Brasil, os processos modernistas, justamente, visavam resgatar o homem do interior, remontar o que seria a nação brasileira a partir da cultura popular. É claro que isso só aconteceu porque era - e ainda é - interessante para os setores hegemônicos, pois é lucrativo o país ser folclórico, assim como é para Minas ser arraigada à tradição popular." (COSTA, 2008, p. 8). Esse tipo de atitude artística valorizou a cultura popular e os regionalismos. "Em um mundo onde as informações circulam velozmente e tendem a homogeneizar as diferentes culturas de seus habitantes, a identidade se torna moeda forte". (COSTA, 2008, p. 7).

ROCHA (2009) acrescenta, também, que, a partir da ideia de que a cultura popular passar a ser supervalorizada a partir dos anos 1960 até os 1980, esta ganha um sentido político e ideológico bastante acentuado, garantindo, nos meios acadêmicos e políticos, uma grande importância. Nesse momento, há uma dissociação entre o que chamam de cultura popular e o folclore. O folclore ganha, então, uma conotação de arcaico e histórico, com fortes influências coloniais, mas que, ao mesmo tempo, disputa com a cultura popular a "aura" de autenticidade. "Contudo, embora implícito, o elemento que parece sustentar a distinção entre o folclore e a cultura popular consiste no desenvolvimento da sociedade urbana, culturalmente marcada por visões de mundo e estilos de vidas modernos". (ROCHA, 2009, p. 224).

Já o termo cultura regional, para PICHLER e MELLO (2012), pode ser definido como uma união, em uma determinada região, das diversas manifestações culturais realizadas por classes diversas. Isso torna o estudo da cultura mais abrangente e complexo. A cultura específica de uma região sofre modificações a partir das relações e intercessões estabelecidas entre as criações da cultura popular e da cultura erudita.

Contudo, em mundo complexo, massificado e fragmentado como o das sociedades contemporâneas, onde não se pode perder de vista o papel da indústria cultural, as fronteiras entre o erudito e o popular, o rural e o urbano, o tradicional e o moderno são relativizadas, mas não superadas (ROCHA, 2009, p. 229). 


\section{CULTURA REGIONAL E MINEIRIDADE}

É exatamente nesse contexto da cultura regional e da relação da cultura em um mundo complexo que se percebe como a montagem teatral de "A Mandioca Brava" se encaixa. A concepção da proposta de montagem calca-se principalmente em aspectos da cultura popular mineira de uma forma ampla. Não apenas de uma região específica do estado, ou de um conjunto de regiões que possuem aspectos semelhantes, mas nas características multiculturais e facetadas apresentadas por uma Minas Gerais que é, ao mesmo tempo, moderna e tradicional, que soma o rural e o urbano de maneira harmônica. Como bem declara Guimarães Rosa sobre Minas Gerais em entrevista para a revista "O Cruzeiro" em 1957:

Sobre o que, em seu território, ela ajunta de tudo, os extremos, delimita,
aproxima, propõe transição, une ou mistura: no clima, na flora, na fauna,
nos costumes, na geografia, lá se dão encontro, concordemente, as
diferentes partes do Brasil. Seu orbe é uma pequena síntese, uma
encruzilhada; pois Minas Gerais é muitas. São, pelo menos, várias Minas
(ROSA, 1957, p. 2)

Essa mineiridade ${ }^{1}$, então, pode ser compreendida como uma impressão de características identitárias particulares da população de Minas Gerais, que podem ser representadas por um conjunto de significados que, por sua vez, produzem sentidos a partir de uma maneira personalizada do mineiro de codificar e decodificar o mundo. Arruda (1999) também oferece sua interpretação sobre o que ele chama de mineirismo: "a realidade social de Minas, no século XIX, encaminhou-se para certa autonomia, criando uma subcultura singular, fruto da amálgama entre o passado e o presente, que se poderia denominar por mineirismo" (ARRUDA, 1999, p.198). COSTA (2010) faz uma reflexão sobre esse processo de mineiridade, afirmando que pode parecer incoerente essa imagem comunicada do mineiro, sendo definido pela mineiridade, principalmente porque Minas Gerais também se insere no contexto atual de globalização.

A cultura em posição central na sociedade assume papel fundamental na construção de sistemas simbólicos, representações culturais e significados. Aqui, procurou-se mostrar que Minas Gerais é uma sociedade tão plural quanto qualquer outra do contexto contemporâneo: por mais que os setores dominantes tentem, não há como se aprisionar a identidade do mineiro em um estojo museológico (COSTA, 2010. p.13).

YÚDICE (2004), porém, propõe a ideia de cultura como recurso, que circula velozmente pelo mundo devido a uma maior permeabilidade entre culturas. "Diferenças regionais e nacionais, entendidas como campos de força diferentemente estruturados que formam o sentido de qualquer fenômeno, (...) são funcionais para o comércio e o ativismo globais." (YÚDICE, 2004, p.12). Ao consumir determinado produto ou bem, as pessoas podem adquirir identificações, trocando velhas experiências por novas. Sendo assim, para o comércio global, as diferenças passam a ser interessantes e lucrativas a partir dos produtos oriundos da diversidade.

HALL (2002), citando Benjamim Schwarz (1986), afirma que as identidades são formadas e transformadas dos pensamentos e das manifestações culturais peculiares

\footnotetext{
${ }^{1}$ Como também pode ser observado nas falas de Guimarães Rosa na mesma reportagem de 1957 para a Revista O Cruzeiro: “Aí está Minas: a mineiridade”. (ROSA, 1957, p. 5)
} 
às pessoas que habitam uma determinada região, a partir do desenvolvimento dos traços de linguagem, da vivência em sociedade, características essas que apresentam peculiaridades semelhantes à de uma nação. “(...) Uma nação é uma comunidade simbólica e é isso que explica seu 'poder para gerar um sentimento de identidade e lealdade" (SCHWARZ, 1986, p. 106 apud HALL, 2002, p. 49). No entanto, para Hall, essas características não são imutáveis. "(...) em vez de falar em identidade como uma coisa acabada, deveria falar de identificação, e vê-la como um processo em andamento." (HALL, 2002, p. 39). Conclui-se que essas características sofrem transformação com o passar do tempo e com a influência de outras culturas, sendo, portanto, identitárias não são imutáveis. Também em HALL (2003) o local de toda cultura de um povo é aquele onde ocorrem embates constantes, a partir da reorganização com as relações globais estabelecidas, onde acontecem processos de: "incorporação, distorção, resistência, negociação, recuperação" (HALL, 2003, p.259). Assim, toda cultura global é permeada por tradições locais, e nenhuma relação de reconhecimento, significação ou tradição, permanece inalterável ou cristalizada, sofrendo os efeitos das influências globais.

ARRUDA (1999) faz uma comparação sobre essa evolução da identidade afirmando que, assim como os mitos que são voltados para as origens, assumir integralmente a memória significa romper as barreiras do tempo, articular o passado com o presente, deixar-se permear pelo passado, ainda que, no presente, retira-se dele os princípios da identidade e estabelece-se empatia pelo mesmo. Para Canclini:

\begin{abstract}
Nunca houve tantos artesãos, nem músicos populares, nem semelhante difusão do folclore, porque seus produtos mantêm funções tradicionais [...] e desenvolvem outras modernas: atraem turistas e consumidores urbanos que encontram nos bens folclóricos signos de distinção, referências personalizadas que os bens industriais não oferecem (CANCLINI, 2003: 22).
\end{abstract}

A montagem de "A Mandioca Brava" se estabelece exatamente no que poderíamos chamar de mineiridade contemporânea, em um processo de hibridação ${ }^{2}$ cultural que conjuga iconografias e musicalidades diversas em interpretações regionais, mas com características atuais. Isso parece tornar o espetáculo mais rico e complexo artisticamente, pois, como afirma Canclini, "Ser artista ou escritor, produzir obras significativas no meio dessa reorganização da sociedade global e dos mercados simbólicos, comunicar-se com públicos amplos, tornou-se muito mais complicado." (CANCLINI, 2003, p. 96).

\title{
4. DESIGN CÊNICO
}

A ABRACE ${ }^{3}$, quando realizou o Seminário de Design Cênico, definiu essa área de atuação como aquela que trabalha os elementos visuais e sonoros da cena, desenvolvendo projetos nos campos da Cenografia, da Iluminação Cênica, do Figurino,

\footnotetext{
${ }^{2}$ Canclini cita que Mikhail Bakthin usou o termo hibridação para definir e caracterizar a coexistência de linguagens cultas e populares na modernidade. "[...] Posto que fomos colonizados pelas nações européias mais atrasadas, submetidos à Contrarreforma e a outros movimentos antimodernos, apenas com a independência pudemos iniciar a atualização de nossos países. Desde então, houve ondas de modernização." (CANCLINI, 2003, p. 67).

3 ABRACE (Associação Brasileira de Pesquisa e Pós Graduação em Artes Cênicas). Disponível em: <http://portalabrace.org/ >. Acesso em 28 abr. 2016.
} 
da Maquiagem Cênica, da Sonoplastia, da Direção de Arte e da Arquitetura Cênica. A área de atividade definida como Design Cênico pode ser uma possibilidade de campo de atuação para os profissionais de Design a partir do conceito de sua formação multidisciplinar. A montagem de um espetáculo teatral pode ser considerada um sistema complexo, que abrange diversas áreas de conhecimentos, tais como planejamento de projeto, processo de criação, contextualização histórica, elementos de percepção, referências estéticas, características formais e simbólicas. Todas essas áreas permeiam tanto a atividade teatral como a do designer.

"De fato, é a percepção sistêmica que caracteriza e estimula a atuação do design na contemporaneidade" (MORAES e KRUCKEN, 2008, p. 26). Essa afirmação pode ser interpretada a partir das várias possibilidades de atuação em diversos segmentos do designer, assim como na configuração e na construção de um espetáculo teatral. Embora o termo Design Cênico comece a se tornar mais popular para aqueles que trabalham ou desenvolvem pesquisa no campo das artes cênicas, como acontece na ABRACE, ainda são poucos os profissionais do teatro que conseguem estabelecer uma conexão de suas atividades com o estudo de design, suas ferramentas, métodos e processos.

Ao assistir a uma montagem teatral, os projetos de cenografia, figurino, iluminação, maquiagem, trilha sonora, coreografia e demais áreas das artes cênicas, podem parecer configurar-se como um conjunto de atividades distintas entre si. No entanto, todos os profissionais responsáveis por cada projeto são imbuídos de demandas criativas convergentes, propostas por um encenador, como em um processo sistêmico e integrado semelhante ao desenvolvido em um projeto de design, cujo objetivo é transpor para o palco uma trama por meio de uma linguagem coerente, significativa e unificada. O Dicionário de Teatro de Patrice Pavis define o papel do encenador teatral como o de uma "Pessoa encarregada de montar uma peça, assumindo a responsabilidade estética e organizacional do espetáculo, escolhendo os atores, interpretando o texto, utilizando as possibilidades cênicas à sua disposição" (PAVIS, 1999 p. 128).

TUDELLA (2012, p.2) afirma que "Aplicar o termo design na cena implica um processo criativo, incluindo questões de estilo, afirmações poéticas, e pode sugerir inventividade." LUPTON e PHILLIPS (2008) acreditam no poder agregador dos princípios do design para um reencontro com a forma e o pensamento visual no processo de criação. Por isso, pode ser importante para essa pesquisa introduzir, com mesmo propósito de design cênico e linguagem visual, o conceito apresentado por PAVIS (1999) de cenografia como "grafia da cena".

BREWSTER e SHAFER (2011) alertam para as questões de estilo e unidade dos elementos que compõem o espetáculo teatral. Da necessidade de um trabalho conjunto em relação à concepção de um espetáculo, que pode ter muitas linguagens, realistas ou não, mas que deve seguir um estilo próprio e integrado, os autores ressaltam que os profissionais devem atuar em harmonia para que o espetáculo que está sendo encenado não perca o sentido para o espectador. Citam como exemplo um espetáculo que possui cenários, figurinos e iluminação expressionistas e uma atuação naturalista, considerando que isso não faz o menor sentido e só provoca a desorientação do espectador.

O espetáculo selecionado como objeto de estudo no desenvolvimento dessa pesquisa, intitulado "A Mandioca Brava", atende a critérios que são essenciais a uma 
ampla análise e discussão sobre a percepção da utilização de características estéticas bem definidas relacionadas à identidade e à cultura mineira com foco em design e território. $\mathrm{O}$ espetáculo tem uma unidade de estilo bastante perceptível relacionada à linguagem textual, sonora e visual (cenografia, iluminação, figurino e maquiagem). 0 espetáculo "A Mandioca Brava" realiza uma verdadeira imersão cultural no universo da cultura mineira, buscando referências visuais e espaciais no artesanato e na arquitetura local, referências de linguagem nas particularidades encontradas nas expressões idiomáticas e no sotaque mineiro, e referências corporais e sonoras nas manifestações culturais que permeiam todo o estado de Minas Gerais.

\section{O ESPETÁCULO}

O texto da montagem de "A Mandioca Brava" é adaptado do original de Nicolau Maquiavel "A Mandrágora", escrito em 1503, o qual apresenta reflexões críticas a respeito de temas comuns em todos os tempos na história da humanidade. A partir de uma comédia leve sobre o comportamento humano, "A Mandrágora" satiriza os seus interesses mais íntimos, como a luxúria, a ganância, as instituições familiares e os papeis representados pela mulher, pela Igreja e pela religiosidade na sociedade.

\footnotetext{
Nota-se que as relações sociais da época em que foi escrita a obra $A$ Mandrágora, não são absurdamente diferentes das que se encontram no século XXI. Ainda há e provavelmente sempre haverá adultérios, pessoas querendo passar por cimas de outras em benefício próprio, chantagens, subornos e afins. Acima de tudo, nota-se que o filósofo italiano Maquiavel, não estava somente preocupado com as relações políticas do Estado naquela época, ele também se preocupou em relatar, mesmo que em peça de teatro, as relações sociais e humanitárias entre homens da época que por sinal se perpetua até os dias atuais (CALAHANI, 2009, p. 8).
}

A versão dessa estória de Nicolau Maquiavel apresentada pelo grupo Spetáculo Casa de Artes não interfere em nada os princípios políticos e morais apresentados pelo autor. A proposta pretendeu aproximar um pouco mais o texto, que no original parece hermético, do público contemporâneo, utilizando uma linguagem mais popular e atualizando os temas apresentados. Uma das características apresentadas pelo texto de Maquiavel é sua atualidade, o que possibilitou ao grupo uma adaptação bem fiel ao texto original, pois a composição das personagens da trama é bastante complexa, muito próxima do nosso cotidiano, de modo que não conseguimos compreende-la de forma maniqueísta. Essa construção possibilitou ao grupo a atualização de personagens e linguagens sem perder a fidelidade apresentada por Maquiavel.

O fim da peça é extremamente original para os padrões da época. Ocorre que A Mandrágora não é uma comédia, por assim dizer, convencional. Seus personagens são complexos e temos dificuldade em estabelecer o bem e o mal. A peça parece pôr em xeque nossa moralidade tradicional ao inviabilizar uma leitura plana e segura do bem e do mal que parecem se inverter constantemente ao longo dos atos (CINTRA, 2011, p. 225).

A produção poderia adaptar apenas a linguagem para o português atual, preservando características europeias e medievais para a montagem, como já aconteceu em outras montagens de textos semelhantes em Belo Horizonte, ou mesmo em nível nacional, algumas produções também optam por esse estilo de adaptação. A proposta de "A Mandioca Brava" parece ultrapassar simplesmente as questões da 
compreensão do texto pelos espectadores e propõe uma imersão dos temas apresentados na obra original dentro do universo mineiro, pretendendo, com isso, fornecer uma maior identificação pelo público.

Adaptações semelhantes de textos clássicos da dramaturgia para universos distintos não são raras de acontecer. O cinema está repleto desse tipo de iniciativa. Mas, retomando o universo teatral de Minas Gerais, uma das adaptações mais famosas dentro do teatro mineiro é a montagem de "Romeu e Julieta", de Willian Shakespeare, pelo diretor Gabriel Villela com o Grupo Galpão em 1992. A proposta de Villela trazia para Shakespeare o universo da linguagem visual e sonora de Minas Gerais, mas não trazia a localidade e a temporalidade para Minas Gerais.

Aos poucos Gabriel vai soltando as primeiras idéias da montagem: música de seresta, clãs tradicionais da família mineira, providenciar o encontro de Shakespeare com Minas, guarda-chuvas e tochas. Forma e conteúdo. Parece que ele pensa o conteúdo a partir da forma. É um procedimento diverso de filosofar, mas o qual compreendo cada vez mais. (BRANDÃO, 1999, p. 25)

No texto falado do espetáculo, as localidades permaneceram europeias, e os atores não se utilizavam o sotaque e as expressões idiomáticas mineiras. Segundo BRANDÃO (1999), o prólogo, escrito por ele, recebeu características da linguagem de um texto de Guimarães Rosa, enquanto Villela se manteve extremamente fiel ao texto original e ao universo palaciano de Shakespeare.

A proposta de "A Mandioca Brava" aprofunda esse aspecto trazendo, também, para a leitura do texto original as localidades mineiras e o sotaque na linguagem, além da utilização de expressões idiomáticas tipicamente mineiras. A adaptação de "A Mandioca Brava" foi proposta para que a estória transcorresse temporalmente no presente, em alguma cidade do interior de Minas Gerais, para dentro da cultura popular mineira, aproveitando toda a ironia e o humor apresentados pelo autor.

\footnotetext{
Uma dessas peculiaridades cabe à fala: além do sotaque característico e regionalismos lingüísticos, atribui-se ao mineiro um jeito particular de falar, conhecido como mineirês. Essa especificidade lingüística é muito mais própria do interior, do que da capital de Minas Gerais, mas é manifesto que esta também se faz presente no vocabulário dos belorizontinos. Nesse sentido, tanto o Grupo Galpão, quanto o Corpo, possuem trabalhos que logo no título sinalizam esse regionalismo, porém não antecipam o tipo de encenação ou exploram uma imagem caipira (COSTA, 2010, p. 11-12).
}

O Espetáculo "A Mandioca Brava” coloca tanto no título quanto em suas expressões elementos linguísticos regionais da mineiridade. Em entrevista fornecida para o programa televisivo Globo Horizonte da Rede Globo Minas, o grupo revelou que o título da montagem teve sua origem na escolha de uma raiz que transmitisse, para os brasileiros, algumas características semelhantes às que a mandrágora transmitia aos europeus. Ambas as raízes são venenosas, mas uma delas pode ser utilizada como produto medicinal e a outra como produto alimentar, sendo que as duas possuem uma tradição mítica, com aparência visual antropomórfica.

A preparação do elenco teve como suporte as matrizes mistas de animais, em uma construção antropozoomórfica inspirada nas esculturas de cerâmica do artista popular mineiro Ulisses Pereira Chaves. "Ulisses produz uma cerâmica escultórica antropozoomórfica de grande dimensão. São figuras sobrenaturais expressionistas e surrealistas" (DALGLISH, 2006, p 166). As características visuais da cerâmica de Ulisses também inspiraram a criação da maquiagem (com tons de marrom e branco) como 
pode ser observado na figura $\mathbf{2}$ a seguir. A trilha sonora original, tocada e cantada ao vivo pelos atores, mesclando elementos de canções regionais e ritmos populares, antigas e modernas, realizando um passeio por sonoridades e canções de vários estilos representantes da diversidade cultural do estado de Minas Gerais, são geralmente cômicas e dão uma leveza para alguns temas abordados pela peça, observado na figura 3 a seguir. É interessante saber que o próprio Maquiavel, em seu texto original "A Mandrágora", propunha letras de canções para o prólogo e as mudanças de ato com o sentido de facilitar a compreensão pelo público presente.

Para representar a peça em Faenza a pedido do grande amigo de nosso autor, Francesco Guicciardini. Diante da mediocridade da plateia, ele sugeriu a Maquiavel que escrevesse algumas canções para serem usadas entre os atos, o que foi prontamente atendido e enviado por carta ainda no começo do ano, uma vez que o projeto original, que acabou não se cumprindo, era de realizar a apresentação no carnaval. Seja como for $A$ Mandrágora foi o maior sucesso que colheu Maquiavel em vida (BIGNOTTO, 2014, p. 7).
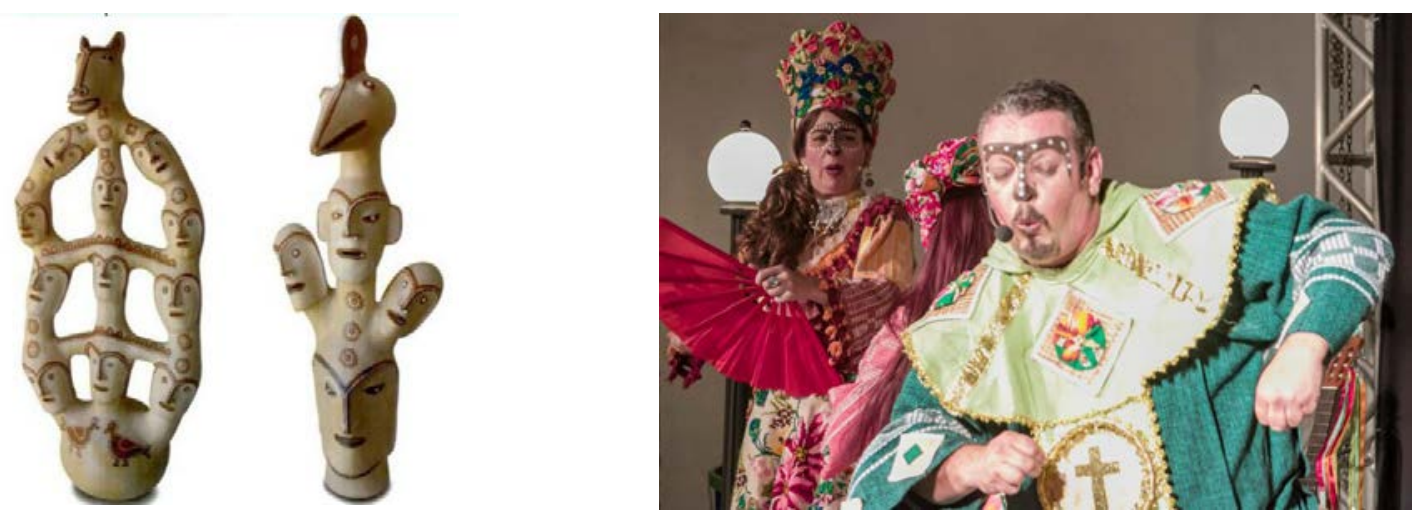

Figura 2 - Foto da Cerâmica do artista Ulisses Pereira Chaves do livro “Noivas da seca: cerâmica popular do Vale do Jequitinhonha", de Lalada Dalglish, p. 166, em relação à foto do espetáculo "A Mandioca Brava".

Fonte: Marco Aurélio Prates (https://www.facebook.com/amandiocabrava/photos_stream)
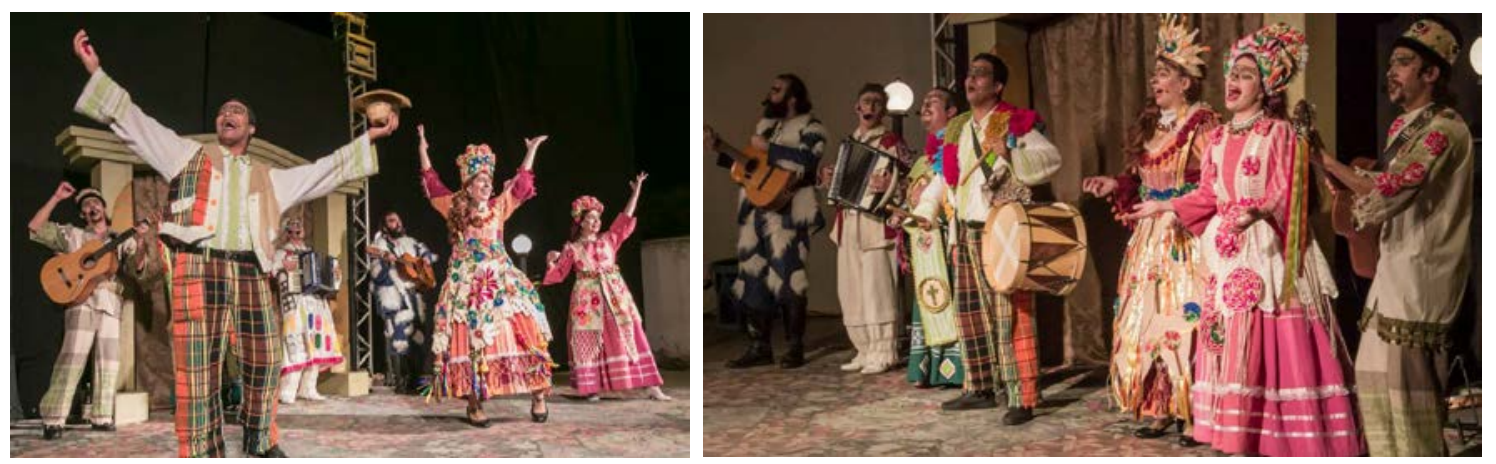

Figura 3 - Composição com duas cenas musicadas em diferentes momentos do espetáculo Fonte: Marco Aurélio Prates (https://www.facebook.com/amandiocabrava/photos_stream)

A cenografia e a espacialização, através da concepção de encenação, utilizaram da iconografia presente no artesanato e na arquitetura interiorana, e, além de ambientar, envolveu o espectador por todos os lados dispondo as cenas por todo espaço cênico. Em apresentações na rua, o envolvimento do espectador foi ainda maior, aproveitando-se da própria arquitetura local da praça onde o espetáculo se 
apresentou. A configuração é sempre de ambientação externa, de uma praça localizada em uma pequena cidade do interior. Com a utilização da iluminação as características de praça se ampliavam. Já a caracterização dos personagens a partir dos figurinos e adereços seguiu essa mesma linha de concepção e trouxe elementos artesanais, como a cestaria, os bordados, o crochê e tricô, as rendas, as pedrarias e sementes, além de tecidos rústicos de fibra natural (teares artesanais), típicos da cultura mineira, para composição da vestimenta de cada personagem, utilizando esses elementos oriundos do artesanato mineiro de forma inusitada, de maneira quase alegórica e figurativa. Todos os elementos visuais e espaciais podem ser observados na composição formada pela figura 4 com cenas do espetáculo a seguir.
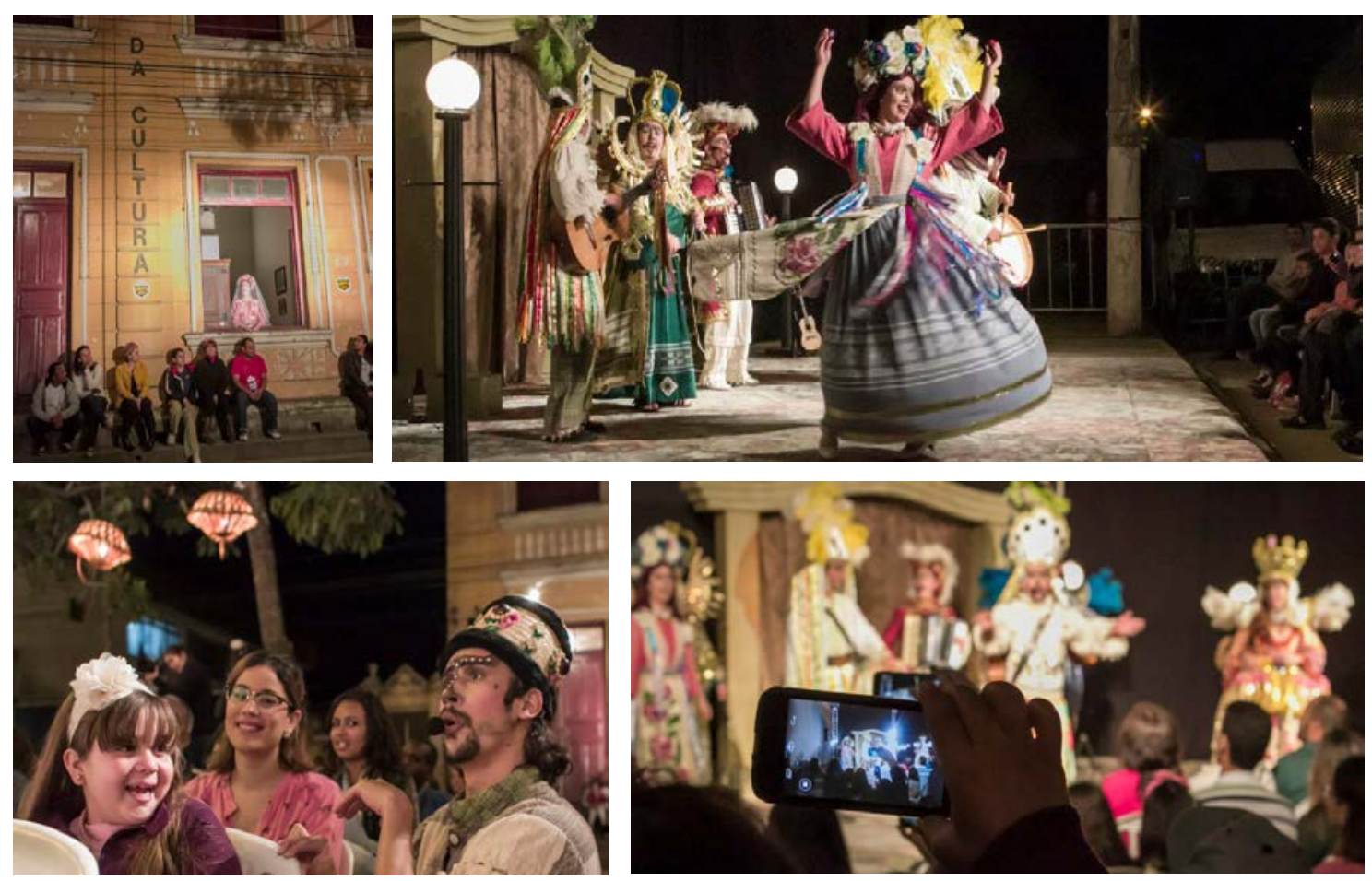

Figura 4 - Composição com quatro cenas em diferentes momentos do espetáculo Fonte: Marco Aurélio Prates (https://www.facebook.com/amandiocabrava/photos_stream)

\section{CONCLUSÃO}

O que Maquiavel retrataria se escrevesse "A Mandrágora" nos dias de hoje? Se ainda residisse em Minas Gerais, que ambiente seria esse representado por ele? Percebe-se que a montagem do espetáculo "A mandioca Brava" tentou responder exatamente a questões como essa. O grupo realizou uma intensa pesquisa do ser mineiro a partir da linguagem, dos costumes, do artesanato, da musicalidade etc. Se, como declara ONO (2004), uma das funções do design é tornar os produtos comunicáveis por suas características simbólicas, pode-se dizer que o grupo atingiu seu objetivo projetual. O grupo fundiu características de linguagem, da musicalidade e imagens da cultura popular com uma proposta de encenação teatral extremamente moderna, apresentando-se tanto em teatros de pequeno e grande porte como na rua. Observa-se que as referências identitárias de segmentos populares não foram limitadas apenas à condição de espectador, mas de participante e fonte de inspiração de todo processo de execução - montagem e apresentação - do espetáculo. 
SCHNEIDER (2010) afirma que o design é um fenômeno de cultura de massas, participando efetivamente na construção do gosto e de juízos de valor, sendo a arte mais vivaz e mais popular do presente. Ao fazer uso de elementos próprios de uma região, a montagem de "A Mandioca Brava" consegue promover uma conexão de reconhecimento e identidade com o espectador local; e ainda, a partir do efeito de globalização, amplia seu repertório de comunicação, possibilitando atingir públicos de outras regiões ou mesmo de outras culturas, ao articular os elementos da cultura regional com questões universais. O grupo se utiliza claramente do conceito de design e identidade como de design e território como fonte primordial de sua encenação, evitando a homogeneização das diferentes culturas e estabelecendo a valorização das características identitárias de sua região.

\section{REFERÊNCIAS}

ABRACE - Associação Brasileira de Pesquisa e Pós Graduação em Artes Cênicas. Disponível em: <http://portalabrace.org/> Acesso em 02 nov. 2015.

A MANDIOCA BRAVA. Globo Horizonte. Belo Horizonte: Rede Globo Minas. 12 de janeiro de 2014. Programa de TV. Disponível para acesso em: <https://youtu.be/UCWRRNW1p-E> Acesso em 10 jun. 2016.

ARRUDA, Maria Arminda do Nascimento. Mitologia da mineiridade: 0 imaginário mineiro na vida política e cultural do Brasil. São Paulo: Brasiliense, 1999.

BIGNOTTO, Newton. Política e vida privada na Mandrágora de Maquiavel. Cadernos de Ética e Filosofia Política - Dep. Filosofia - Universidade de São Paulo. 2014. Disponível em: <http://www.revistas.usp.br/cefp/article/viewFile/85744/88506> Acesso em 08 nov. 2015.

BRANDÃO, Carlos Antônio Leite. Grupo Galpão: diário de montagem. Livro1 Romeu e Julieta. Belo Horizonte: Editora UFMG, 1999.

BREWSTER, Karen. SHAFER, Melissa. Fundamentals of Theatre Design. New York: Allworth Press. 2011.

CANCLINI, Néstor García. Culturas híbridas: estratégias para entrar e sair da modernidade. São Paulo: Edusp, 2003.

CALAHANI, Aline Ignácio. BRITO, Luciana. $\mathbf{O}$ adultério e as relações sociais em $\mathbf{A}$ Mandrágora de Nicolau Maquiavel. Universidade Estadual do Norte do Paraná. VI Seminário de Iniciação Científica - SóLetras - 2009. Disponível em:

<http://www.uenp.edu.br/trabalhos/cj/anais/soLetras2009/Aline\%20lgn\%C3\%A1cio\% 20Calahani.pdf> Acesso em 08 fev. 2016.

CINTRA, Rodrigo Augusto Suzuki Dias. O Príncipe e A Mandrágora: filosofia política e teatro em Maquiavel. Revista de Direito Mackenzie. Volume 5, número 2, 2011.

Disponível em: <http://congressoletras.mackenzie.br/index.php/rmd/issue/view/341> Acesso em 08 fev. 2016.

COSTA, Fernanda M. Alves. A representação da mineiridade: o corpo e o galpão das gerais. Facom-UFBa - Salvador-Brasil, 2010. Disponível em: <http://www.cult.ufba.br/wordpress/24557.pdf> Acesso em 01 fev. 2016. . Grupo galpão: a mineiridade na cena contemporânea. 
Facom-UFBa - Salvador/Brasil, 2008. Disponível em:

<http://www.cult.ufba.br/enecult2008/14402.pdf> Acesso em 01 fev. 2016.

DALGLISH, Lalada. Noivas da seca: cerâmica popular do Vale do Jequitinhonha. São Paulo: Editora UNESP, 2006.

HALL, Stuart. A identidade cultural na pós-modernidade. Rio de Janeiro: DP \& A editora, 2002.

. Notas sobre a desconstrução do popular. Da Diáspora - Identidades e Mediações Culturais. Belo Horizonte: UFMG, 2003.

LUPTON, Ellen; PHILLIPS, Jennifer Cole. Novos Fundamentos do Design. São Paulo: Cosac Naify, 2008.

MORAES, Dijon de (org.). KRUCKEN, Lia. (org.) Design e multiculturalismo. Cadernos Avançados em Design. Belo Horizonte: EdUEMG. 2008.

ONO, M. M. Design, cultura e identidade, no contexto da globalização. Revista Design em foco, julho-dezembro, vol I, no 001. Salvador: Universidade do Estado da Bahia, 2004. Disponível para acesso em: <http://www.redalyc.org/pdf/661/66110107.pdf> Acesso em 02 fev. 2016.

PAVIS, Patrice. Dicionário de teatro. São Paulo: Perspectiva, 1999.

PICHLER, R.F; MELLO, C.I de. O Design e a Valorização da Identidade Local. Revista Design \& Tecnologia - Edição no 4. 2012. Disponível em:

<http://www.pgdesign.ufrgs.br/designetecnologia/index.php/det/issue/view/5>. Acesso em 04 fev. 2016.

PRATES, Marco Aurélio. A Mandioca Brava. Belo Horizonte: 2014. Acervo de imagens da página do Facebook do espetáculo A Mandioca Brava - Disponível em:

<https://www.facebook.com/amandiocabrava/photos_stream>. Acesso em $04 \mathrm{fev}$. 2016.

ROCHA, Gilmar. Cultura popular: do folclore ao patrimônio. Mediações - Revista de Ciências Sociais, Volume 14 nำ1. Programa de Pós-Graduação em Ciências Sociais da Universidade Estadual de Londrina. 2009. Disponível em:

<http://www.uel.br/revistas/uel/index.php/mediacoes/index> Acesso em 04 fev. 2016.

ROSA, João Guimarães. Aí está Minas: a mineiridade. publicado na revista "O Cruzeiro", em 25 de agosto de 1957. Disponível em:

<http://www.jornalopcao.com.br/posts/opcao-cultural/aiesta-minas-a-mineiridade> Acesso em 01 fev. 2016.

SCHNEIDER, B. Design - uma introdução: $O$ design no contexto social, cultural e econômico. São Paulo: Editora Blücher, 2010.

TUDELLA, Eduardo. Design, Cena e Luz: anotações. Escola de Teatro: Revista Alberto, no 3, p. 11 a 24. São Paulo, 2012.

YÚDICE, George. A conveniência da cultura: usos da cultura na era global. Belo Horizonte: Editora UFMG; 2004. 